Published in Global and Planetary Change 44 (1-4): 73-81, 2004

\title{
The 2003 heat wave as an example of summers in a greenhouse climate? Observations and climate model simulations for Basel, Switzerland
}

\author{
Martin Beniston ${ }^{1}$ and Henry F. Diaz ${ }^{2}$ \\ 1: Department of Geosciences, University of Fribourg, Switzerland \\ 2: NOAA/OAR/CDC, Boulder, Colorado, United States
}

\begin{abstract}
The heat wave that affected many parts of Europe during the course of summer 2003 may be a harbinger of summers that could occur more regularly in a future climate, under enhanced greenhouse gas concentrations. Switzerland was not exempt from the 2003 heat wave and, indeed, the previous absolute maximum temperature record dating back to the middle of the $20^{\text {th }}$ century was exceeded by over $2^{\circ} \mathrm{C}$. Regional climate simulations undertaken for the European region emphasize the fact that summers will become progressively as hot as the 2003 event, such that in the latter part of the $21^{\text {st }}$ century, it is likely to become the norm. On the basis of this study, the 2003 event should be considered as a "shape of things to come" and thereby prompt timely decision making in terms of appropriate adaptation and mitigation strategies.
\end{abstract}

\section{Introduction}

The record heat wave that affected many parts of Europe during the course of summer 2003 has been seen by many as a "shape of things to come", reflecting the extremes of temperature that summers are projected to have in the later decades of the $21^{\text {st }}$ century (Beniston, 2004; Schär et al., 2004). The heat wave resulted in absolute maximum temperature records exceeding for the first time in many locations in France, Germany, the United Kingdom, and Swizerland records that had stood since the 1940s and early 1950s, according to the information supplied by national weather agencies and highlighted in the annual report of the World Meteorological Organization (WMO, 2003). Research by Pfister et al. (1999), based on written historical archives, indeed suggest that 2003 is likely to have been the warmest summer since 1540 , when a similarly robust high pressure system was centered on the English Channel, resulting in anomalously early harvests and strong hydrological deficits in numerous European rivers.

This short paper will report on trends in average summer maximum and minimum temperatures (JuneJuly-August means; hereafter referred to as summer Tmax and summer Tmin, respectively) at a representative site in Switzerland, namely Basel located at $367 \mathrm{~m}$ above sea-level, in the north-western part of Switzerland close to the French and German borders. The mean and extremes of average summer temperatures have been analyzed to assess to what extent the 2003 heat wave represents a significant change since the beginning of the $20^{\text {th }}$ century, and how this event compares with trends that are projected by regional climate models for a future climate forced by enhanced concentrations of atmospheric greenhouse gases.

The 2003 event in Europe was associated with a very robust and persistent blocking high pressure system that some weather services suggested may be a manifestation of an exceptional northward extension of the Hadley Cell. Figure 1 shows the very high average monthly levels of the $850 \mathrm{hPa}$ geopotential for June, July and August. Already a record month in terms of maximum temperatures, June exhibited high geopotential values that penetrated northwards towards the British Isles. In July, there was a pause in this northward extension, that resulted in the high but not exceptional temperatures recorded in many parts of Europe, but August saw the greatest northward extension and longest persistence of record-high temperatures. The anomalies of the $850 \mathrm{hPa}$ geopotential are illustrated in the right-hand set of graphs in Figure 1, and serve to highlight the upward deformation of the pressure surface, with strongest anomalies centered over the Alps in June and extending as far as Scotland in August. This exceptional behavior was also observed for the $500 \mathrm{hPa}$ geopotential height throughout the summer months, and the French weather service MeteoFrance recorded a $500 \mathrm{hPa}$ altitude of 5,900 m above sea-level; this represents a large upward deformation of the $500 \mathrm{hPa}$ surface of compared to its average altitude in a standard 
atmosphere. The reader is reminded here that an extension of the thickness of the $500-1000 \mathrm{hPa}$ layers by $10 \mathrm{~m}$ corresponds to a surface warming in the layer by roughly $1^{\circ} \mathrm{C}$. The $30-40 \mathrm{~m}$ anomalies measured at the height of the heat wave thus correspond to a lower tropospheric warming over $4^{\circ} \mathrm{C}$ or more. An exacerbating factor for the temperature extremes was certainly the lack of precipitation in many parts of western and central Europe, leading to much-reduced soil moisture and surface evaporation and evapotranspiration, and thus to a corresponding positive feedback effect.

\section{Insert Figure 1 here}

Press reports and specialized agency documents (e.g., WHO, 2003) have reported on some of the severe impacts of the heat wave on a range of environmental and socio-economic sectors. Perhaps the most dramatic impact, at least partially attributable to the heat wave but also embedded in a wide range of economic and social problems, was the large numbers of excess deaths in France, Italy, and Spain in particular. Over 20,000 people are believed to have died (11-14,000 in France alone) during the heat wave. The 2003 heat wave also impacted severely upon the agricultural sector, with losses of several hundred million Euros in Germany, Italy, and the United Kingdom, and in the billion-Euro range in France. Many major rivers such as the Po in Italy, the Rhine in Germany, and the Loire in France were at recordlow levels, resulting in serious problems for irrigation, cooling of electricity power-generating stations, and toxicity through the proliferation of cyanobacteria. Some mountain glaciers in the Alps lost up to 10\% of their mass during the three months of the heat wave, while an unusually large number of rock falls in the mountains was attributed to permafrost thawing resulting from the exceptionally warm and persistent temperatures recorded at high elevations during much of the summer.

\section{Features of the 2003 heat wave in Switzerland}

Switzerland entered the heat wave at the same time as most other parts of Europe. In Basel, the $30^{\circ} \mathrm{C}$ threshold, that corresponds roughly to the $90^{\text {th }}$ percentile of maximum daily temperatures at that location, had been exceeded already on June 4, and also at other locations such as Geneva and Zurich; the last day when temperatures exceeded this threshold was August 27. During the summer of 2003, the absolute temperature record for Switzerland was reached on August 2 in Grono (an Italian-speaking village in the south-eastern canton of Grisons) with a reading of $41.1^{\circ} \mathrm{C}$, thus exceeding the previous all-time high temperature record of $39.0^{\circ} \mathrm{C}$ held by Basel since July 1947. Figure 2 shows the daily evolution of maximum temperatures during the three summer months of 2003. A first heat wave began in June, followed by a second rather modest period in July, and the strongest and most persistent episode observed in the first half of August.

\section{Insert Figure 2 here}

Figure 3 shows the anomalies of minimum and maximum daily temperatures, averaged over the three summer months of June, July, and August (JJA) from 1901 to 2003. In terms of both nocturnal and diurnal temperatures, the 2003 event clearly stands out as a unique and unprecedented event. In some parts of the country, monthly average maximum temperatures were more than $6^{\circ} \mathrm{C}$ above the norm in June and August; in Basel, the anomaly of the three-month average for $\operatorname{Tmin}$ is over $4.1^{\circ} \mathrm{C}$, and $5.9^{\circ} \mathrm{C}$ for the summer Tmax anomaly. Precipitation deficits resulting in the positive temperature feedbacks alluded to in the preceding introductory section already began in January 2003 in most parts of the country, with very low precipitation amounts at the crucial start of the summer in June with less a quarter of the normal June rainfall (21 mm compared to the 1961-1990 norm of $87 \mathrm{~mm}$ ). Until November 2003, precipitation levels remained well below their long-term mean values based on the 1961-1990 reference period in Basel and elsewhere in the alpine domain; the JJA precipitation total for Basel was $110 \mathrm{~mm}$ compared to a long-term average value of more than $250 \mathrm{~mm}$. Under such circumstances, the soil moisture deficit and humidity stress on vegetation imply unusually strong sensible heat fluxes directed from the surface to the atmosphere, thereby increasing the extremes of temperature beyond the thresholds they would have otherwise attained under normal precipitation conditions.

Insert Figure 3 here 
The 2003 event comes after a series of summers that appear relatively uneventful that followed a major peak in temperatures in the middle of the $20^{\text {th }}$ century, from the early 1940 s to the mid 1950 s that FriisChristensen and Lassen (1991) attribute, at least partially, to unusual solar luminosity output. The 1947 summer saw average maxima at $5^{\circ} \mathrm{C}$ above the long-term average value; since then, positive anomalies of just over $2^{\circ} \mathrm{C}$ have been recorded during the summers of 1976, 1983, and 1994, but none comes close to the 2003 event. Unlike the 1947 heat wave that strongly affected the alpine area and many other parts of Europe, the summertime minimum temperature anomaly far exceeded that of the 1947 Tmin anomaly (that was less than $1^{\circ} \mathrm{C}$ ). Indeed, the fact that night-time temperatures did not cool off to any great extent at the time when daily temperatures were extreme was one contributing factor to the excess mortality related to the heat wave; in physiological terms, if the human body cannot recover from diurnal heat stress during cool nights, then there is a compounded heat stress effect that can be potentially deadly for sensitive persons (generally the elderly and very young children).

According to a study conducted by Beniston (2004), the 2003 event does not break all records, according to the statistics chosen. There were 8 fewer days in 2003 compared to the previous record 1947 heat wave during which temperatures exceeded $30^{\circ} \mathrm{C}$, while in terms of persistence, the successive number of days with a $30^{\circ} \mathrm{C}$ threshold exceedance in 2003 is identical to a the 1911 heat wave, but less than the 1947 or 1976 heat waves; however, as already mentioned, the 2003 event has a compounding heat stress effect through very high minimum temperatures compared to the previous heat waves recorded in the course of the $20^{\text {th }}$ century. The 2003 event thus constitutes a "climatic surprise" that is likely to occur with increasing frequency in the latter part of the $21^{\text {st }}$ century, as will be discussed later.

It is well known that surface temperatures in the North Atlantic Ocean exhibit considerable decadal scale variability (Schlesinger and Ramankutty, 1994), and has a fundamental influence in modulating the climate of Europe (Terray and Cassou, 2002; Sutton and Hodson, 2003). Inspection of Figure 3 shows that the record of summer temperature in Basel region exhibits considerable interannual and decadal-scale variability. It has also been shown that Atlantic sea surface temperature (SST) changes modulate the climate of western Europe through remote air-sea interactions, known as teleconnections (Wang, 2002). A key mode of variability of Atlantic SST is known as the Atlantic multidecadal oscillation (AMO) (Enfield and Mestas-Nuñez 2000; Enfield et al., 2001). Figure 4 illustrates the changes in this mode of SST North Atlantic SST variability. Note that the low-frequency variations in SST mimic to a considerable extent the variability in summer temperatures in Basel displayed in Figure 3.

\section{Insert Figure 4 here}

Climate changes associated with the increasing greenhouse-gas loading of the atmosphere (IPCC, 2001) will act in concert with the changes in North Atlantic SST illustrated in Figure 4, and either exacerbate or diminish its impact on European climate in the future. The temperature changes that are illustrated in Figure 3 exhibit considerable decadal variance. It should be kept in mind that in a future warmer world, these decadal fluctuations, which are intrinsic characteristics of the climate system, may add considerably to the seasonal distributions of daily temperature values, such that even in the first half of the present century, hot summers in Europe could become much hotter than in the past, faster than is projected by some of the global climate models.

Looking to the future, a number of regional climate model simulations have been undertaken in the context of a European network program entitled PRUDENCE, coordinated by the Danish Meteorological Institute (DMI). The models are based on general circulation model results that make use of a scenario implying relatively high greenhouse-gas emission levels (the IPCC A-2 Scenario, discussed by Nakicenovic et al., 2000). Among the regional climate model simulations undertaken in the context of PRUDENCE, results from the HIRHAM4 model of the DMI will be shown here (Christensen et al., 1998). The HIRHAM4 model provides results related to temperature trends that are very similar to those of the other regional model simulations over Europe, so that the results discussed here can be considered representative of the range of RCM outputs. 
HIRHAM4 model results for contemporary climate (1961-1990) show that the statistics of temperature over Europe are in reasonable agreement with observations, both in terms of the means and the higher statistical moments of mean, minimum, and maximum temperatures, thereby allowing some confidence when analyzing the temperature statistics for future climatic conditions based on the A2 greenhouse-gas emissions scenario. The scenarios developed in by Nakicenovic et al. (2000) for the Intergovernmental Panel on Climate Change take into account possible changes in population, social and economic development, technology, resource use, and pollution management, each of which contributes to varying degrees to emissions. The A2 scenarios assume little change in economic behavior compared to today and can thus be considered to be in the high range of possible emission futures. In addition, the rising population levels and limited international collaboration on resource and environmental protection that the A2 scenarios assume will serve to exacerbate the problem of emissions.

\section{Insert Figure 5 here}

Using the results at the grid-point closest to Basel, the HIRHAM4 model points to a mean increase in summer average $\operatorname{Tmax}$ by over $5.2^{\circ} \mathrm{C}$ from $23.6^{\circ} \mathrm{C}$ to $28.8^{\circ} \mathrm{C}$ under future climatic conditions (i.e., for the period 2071-2100) compared to the current reference period 1961-1990. It is possible to compare the probability density functions (PDF) of Tmax for different periods, as illustrated in Figure 5, where Gaussian fits have been applied to the JJA Tmax data for the 1961-1990 period (both observations and HIRHAM4 model results for this same period), the 2071-2100 future climate, and the 2003 event. The HIRHAM4 results are in good agreement with the observations, providing a certain degree of confidence as to the model's capability of reproducing current climate and its future evolution. The change in mean between the contemporary (curve A) and future periods (curve B) is accompanied by a change in the variance of the distribution, which is a feature that has already been observed in other studies (Katz and Brown, 1992). What may be considered to be an extreme event at or beyond the $90^{\text {th }}$ percentile under current climate, according to the definition provided by the Intergovernmental Panel on Climate Change (IPCC, 2001) becomes the median by the second half of the $21^{\text {st }}$ century. For the 1961-1990 period, less than $10 \%$ of summer maximum temperatures exceed $30^{\circ} \mathrm{C}$, while for the $2071-2100$ period, the $30^{\circ} \mathrm{C}$ threshold is exceeded almost $50 \%$ of the time. This is a feature that has also been observed in the statistics of the 2003 event, where the shifts in mean and extremes by $6^{\circ} \mathrm{C}$ compared to the 1961-1990 average in Basel are close to the changes expected from greenhouse gas forcing by 2100.

Figure 6 shows the slope of the linear regression fit between summer mean Tmax and the $90^{\text {th }}$ quantile for both current and future summers. It is seen that the slope for both sets of points is almost identical, with a highly significant correlation coefficient. Mean summer Tmax in Switzerland can thus be used with a high degree of confidence as an empirical predictor of the type of extreme that may occur during a particular summer.

\section{Insert Figure 6 here}

While all the statistics of the 2003 and the 2071-2100 summer maximum temperatures are not in perfect accord, the fact that the probability density function of summer maximum temperature for 2003 lies entirely within the future range projected by the HIRHAM4 model suggests that the recent event may be considered as a close analog to the summers that are likely to occur with much greater frequency in the future as the atmosphere responds to increases in greenhouse gases under the IPCC SRES A2 scenario. The statistics of the previous record heat waves of 1947 and 1976 are far closer to those of the 1961-1990 period both in terms of means and in the higher quantiles of the temperature PDF. Although only the Basel observational site has been presented here, the other low-level locations studied in Switzerland (but not shown here) exhibit identical statistical behavior.

\section{Insert Figure 7 here}

Figure 7 compares the evolution of summer mean maximum temperatures and their $90 \%$ quantile values for 30 years during the reference period 1961-1990 and the future climatic regime projected for 20712100. In order to highlight the exceptional nature of the 2003 heat wave, both the mean and the $90^{\text {th }}$ percentile have been added in the form of horizontal lines; this diagram confirms the conclusions drawn 
from the Gaussian distributions of Figure 5, where the 2003 event is clearly more closely related to what may be expected in the future "A2 climate" rather than contemporary climatic conditions. While for the reference period, mean summer Tmax never reaches the $30^{\circ} \mathrm{C}$ threshold, this is exceeded on several occasions in the future climate. Similarly, a cursory analysis of the behavior of the $90 \%$ quantile shows that between 1961-1990, the upper extreme of maximum temperature was confined in the range $28-34^{\circ} \mathrm{C}$, whereas for $2071-2100$, the range is projected to be shifted within the range of $32-40^{\circ} \mathrm{C}$, with even a peak at $45^{\circ} \mathrm{C}$. There is also greater variability in the latter part of the $21^{\text {st }}$ century compared to the $20^{\text {th }}$ century reference period, which is a feature that Schär et al. (2004) suggest will lead to a greater frequency and intensity of heat waves in many parts of Europe. Beniston (2004) notes that the period during which threshold exceedance beyond the $30^{\circ} \mathrm{C}$ limit can be expected will be extended by close to one month. The season during which this threshold may be exceeded is seen in the HIRHAM4 model to begin on average almost two weeks earlier and end more than two weeks later than under current climatic conditions. The total number of days during which the $30^{\circ} \mathrm{C}$ threshold is exceeded is projected to increase almost 5-fold in the future, as it did during the 2003 heat wave, from about 8 days currently in an average summer to over 40 days in the future. As a result of the higher variability that the regional model projects for the future, absolute annual maximum temperatures may reach $48^{\circ} \mathrm{C}$, i.e., about $6-8^{\circ} \mathrm{C}$ more than the temperature records that were observed in Switzerland in 2003.

\section{Conclusions}

In view of the severity of the impacts related to the persistence of elevated temperatures, coupled to the prolonged drought conditions that affected much of Europe throughout the summer of 2003, such as excess deaths recorded in France, Italy, and Spain (WHO, 2003), losses in the agricultural sector in numerous countries, and strongly-reduced discharge in many rivers, the recent heat wave as a "shape of things to come" is a signal that should be given appropriate consideration by decision-makers. Although a single extreme event, however intense, is by no means proof of global warming, the lessons that can be learned from the recent heat wave could be used to help shape future policy response. The appallingly high mortality in Europe in the extreme hot summer of 2003 was certainly related to the excessive heat, and especially to the high minimum temperatures. Society will face considerable challenges in trying to cope with heat waves of similar or even greater magnitude to 2003 that are projected to become more common in the latter decades of the $21^{\text {st }}$ century. The events of summer 2003 in Europe provided a glimpse at some of the negative impacts related to climatic change, not just in the distant future, but in the present.

\section{Acknowledgements}

The authors gratefully acknowledge access to, and use of, the NCEP-NCAR data sets that were used to prepare the set of illustrations in Figure 1. These data sets are available on the public Internet site:

WWW.cdc.noaa.gov/cdc/reanalysis/reanalysis.shtml

\section{References}

Beniston, M., 2004: The 2003 heat wave in Europe: A shape of things to come? Geophys. Res. Letters, 31, L02202

Christensen, O. B., Christensen, J. H., Machenhauer, B., and Botzet, M., 1998: Very high-resolution regional climate simulations over Scandinavia - Present climate. J. Climate, 11, 3204-3229

Enfield, D.B and A.M. Mestas-Nuñez, 2000: Global modes of ENSO and non-ENSO sea surface temperature variability and their associations with climate. In Diaz, H.F. and Markgraf, V. (eds.), El Niño and the Southern Oscillation, Cambridge University Press, 89-112.

Enfield, D. B., Mestas-Nuñez, A. M., and Trimbole, P. J., 2001: The Atlantic multidecadal oscillation and its relations to rainfall and river flows in the continental U.S. Geophys. Res. Lett., 28, 2077-2080. 
Friis-Christensen, E. and Lassen, K., 1991: Length of the solar cycle, an indication of solar activity closely associated with climate. Science, 254, 698-700

IPCC: Climate Change 2001. The Scientific Basis. Cambridge University Press, 881 pp. (2001).

Katz, R. W., and Brown, B. G., 1992: Extreme events in a changing climate: Variability is more important than averages. Climatic Change, 21, 289-302

Nakicenovic, N. et al., 2000: IPCC Special Report on Emission Scenarios. Cambridge University Press, Cambridge, UK and New York, USA, 599 pp.

Pfister, C., et al., 1999: Documentary evidence on climate in sixteenth-century Europe. Clim. Change, 43, 55-110

Schär, C., P.L. Vidale, D. Lüthi, C. Frei, C. Häberli, M. Liniger and C. Appenzeller, 2004: The role of increasing temperature variability in European summer heat waves. Nature, 427, 332-336

Schlesinger, M. E. and Ramankutty, N., 1994, An oscillation in the global climate system of period 65-70 years, Nature, 367, 723-726.

Sutton, R. T. and D. L. R. Hodson, 2003: Influence of the Ocean on North Atlantic climate variability 18711999. J. Climate, 16, 3296-3313.

Terray, L. and C. Cassou, 2002: Tropical Atlantic sea surface temperature forcing of quasi-decadal climate variability over the North Atlantic-Europe region. J. Climate, 15, 3170-3187.

Wang, C., 2002: Atlantic climate variability and its associated atmospheric circulation cells. J. Climate, 15, 1516-1536 (2002).

WHO, 2003: The health impacts of 2003 summer heat-waves. Briefing note for the Delegations of the fiftythird session of the WHO (World Health Organization) Regional Committee for Europe, $12 \mathrm{pp}$.

WMO, 2003: World Meteorological Organization statement on the status of global climate in 2003. WMO publications, Geneva, $12 \mathrm{pp}$. 


\section{Figure captions}

Figure 1. Average monthly values of the $850 \mathrm{hPa}$ geopotential (left) and its anomaly based on the 19611990 average period (right) centered over Europe for June (upper), July (middle) and August 2003 (lower). Numbers are in geopotential meters (gpm) above sea level.

Figure 2. Daily evolution of daily maximum temperatures at Basel, Switzerland (317 $\mathrm{m}$ above sea level), highlighting the successive heat waves that were observed from June to August. The $30^{\circ} \mathrm{C}$ threshold, corresponding to the $90^{\text {th }}$ percentile of Tmax at this location, is represented by the horizontal dashed line.

Figure 3. Departures of summer minimum and maximum temperatures from the 1961-1990 means at Basel (1901-2003).

Figure 4. Time series of detrended North Atlantic monthly SST anomalies. Running 39-month smoothed values in bold line.

Figure 5. Gaussian distributions fitted to the mean summer maximum temperature data at Basel, Switzerland, for the 1961-1990 reference period (A: Observations; A' HIRHAM4 model results), the 20712100 A-2 scenario simulation (B) and the 2003 heat wave (C).

Figure 6. Relationship between summer mean maximum temperature and the $90 \%$ quantile of Tmax under current and future climatic conditions. Linear regression lines, their equations and their correlation coefficients are given for both the 1961-1990 (solid) and 2071-2100 (dashed) periods.

Figure 7. Comparisons of 30 years of summer mean maximum temperatures and the $90 \%$ quantile for the reference period 1961-1990 and the future period 2071-2100. The solid and dashed horizontal lines represent the mean and $90 \%$ quantile for the 2003 summer, respectively. 


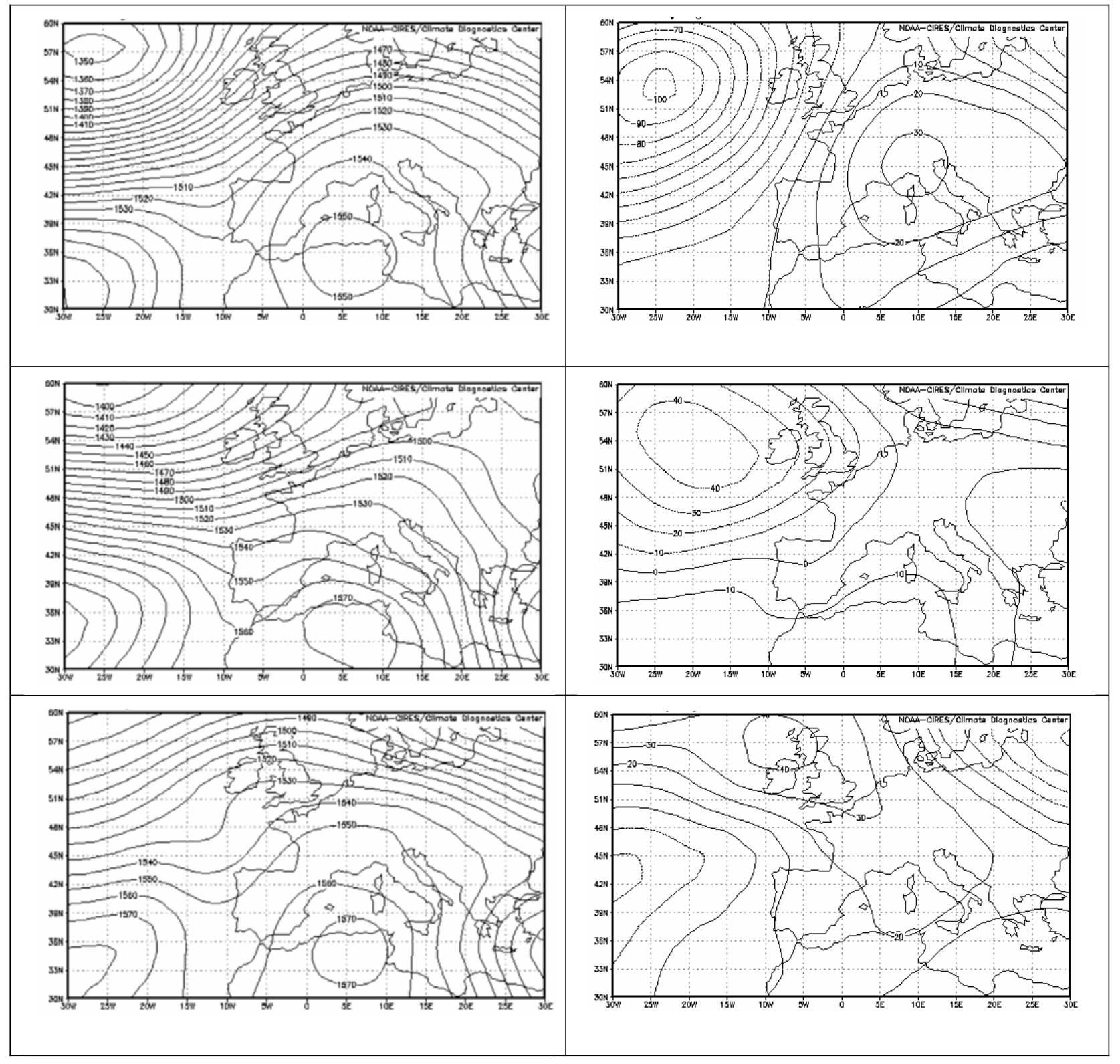

Figure 1. Average monthly values of the $850 \mathrm{hPa}$ geopotential (left) and its anomaly based on the 19611990 average period (right) centered over Europe for June (upper), July (middle) and August 2003 (lower). Numbers are in geopotential meters (gpm) above sea level. 


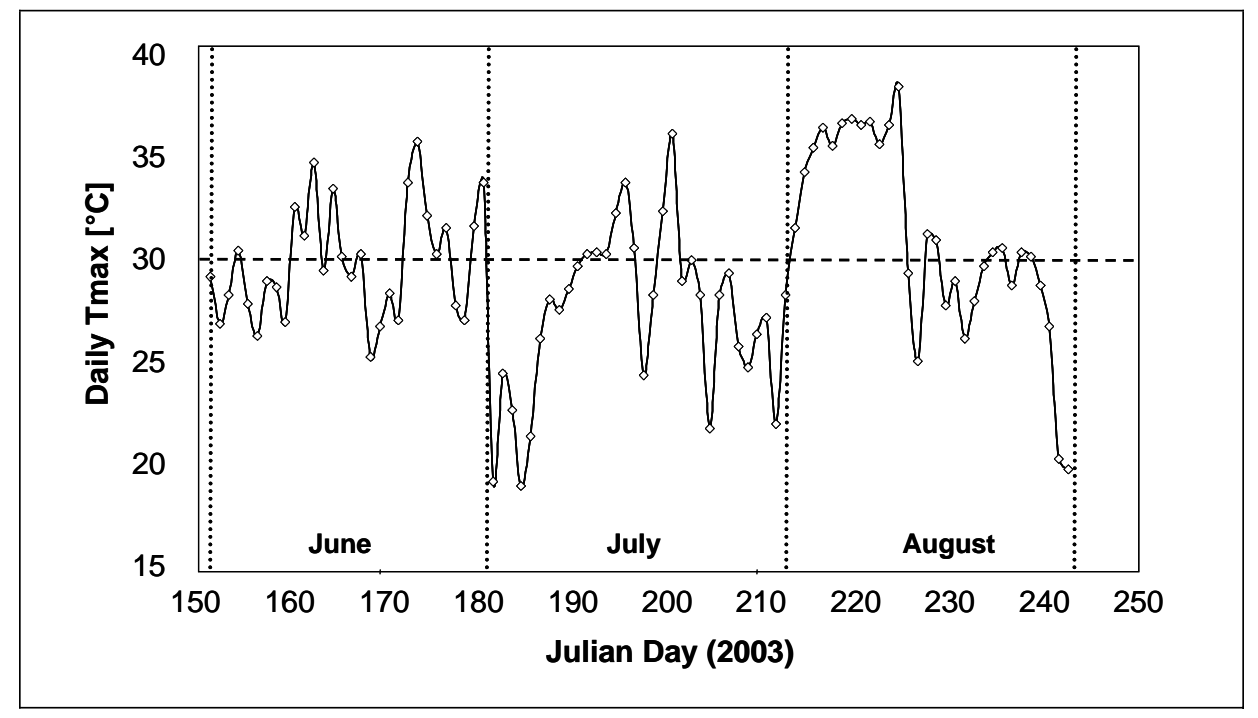

Figure 2. Daily evolution of daily maximum temperatures at Basel, Switzerland (317 $\mathrm{m}$ above sea level), highlighting the successive heat waves that were observed from June to August. The $30^{\circ} \mathrm{C}$ threshold, corresponding to the $90^{\text {th }}$ percentile of Tmax at this location, is represented by the horizontal dashed line. 


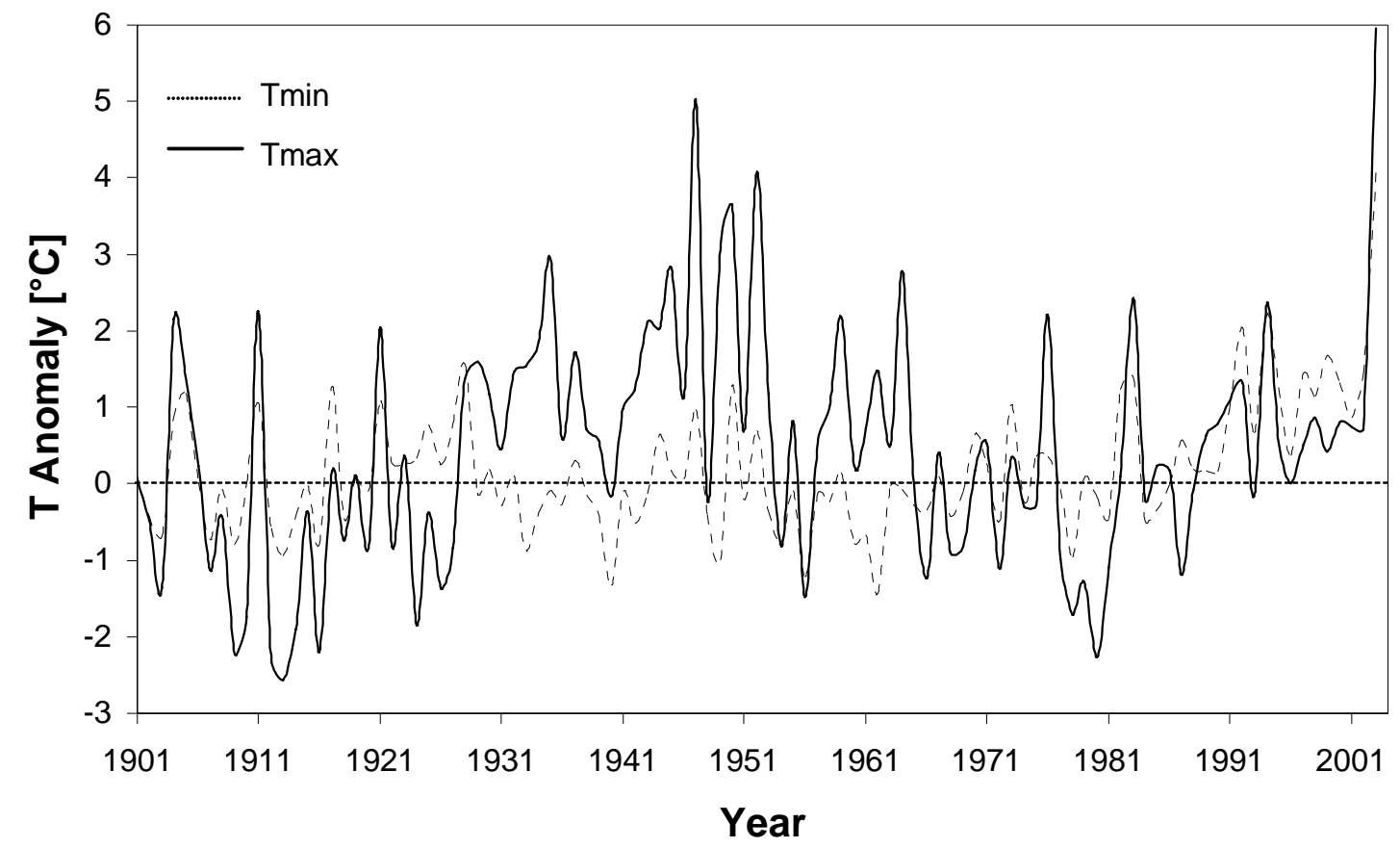

Figure 3. Departures of summer minimum and maximum temperatures from the 1961-1990 means at Basel (1901-2003). 


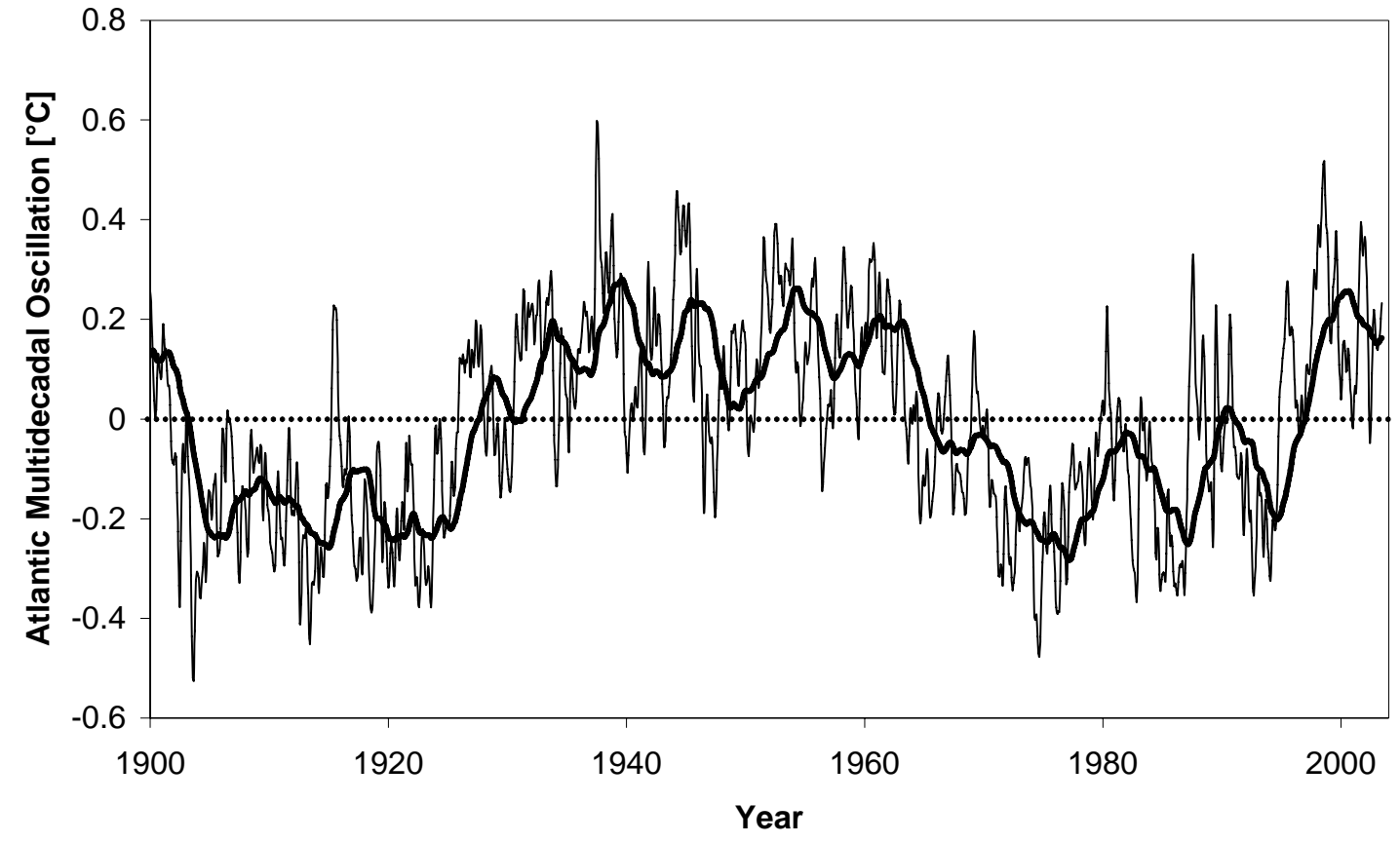

Figure 4. Time series of detrended North Atlantic monthly SST anomalies. Running 39-month smoothed values in bold line. 


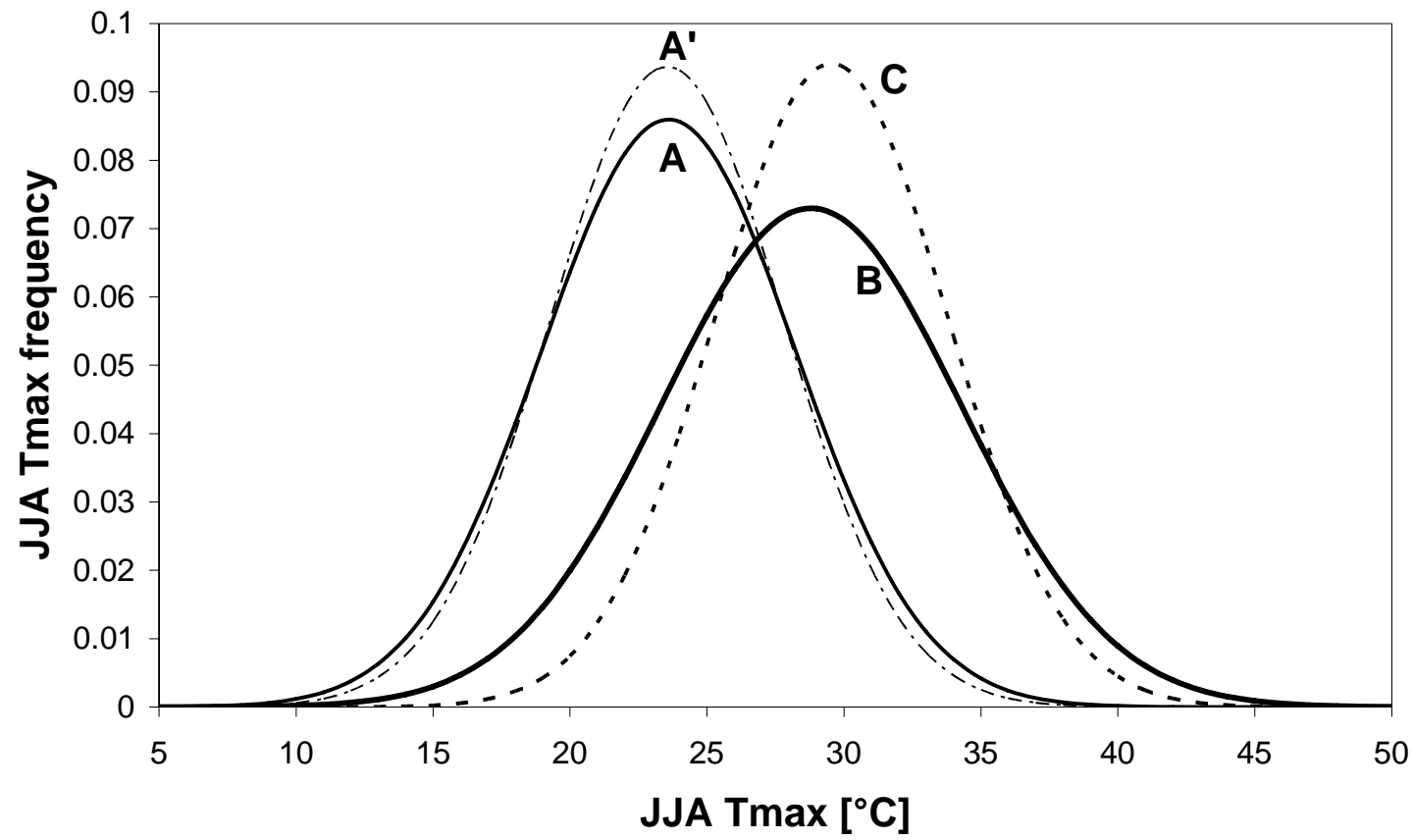

Figure 5. Gaussian distributions fitted to the mean summer maximum temperature data at Basel, Switzerland, for the 1961-1990 reference period (A: Observations; A' HIRHAM4 model results), the 20712100 A-2 scenario simulation (B) and the 2003 heat wave (C). 


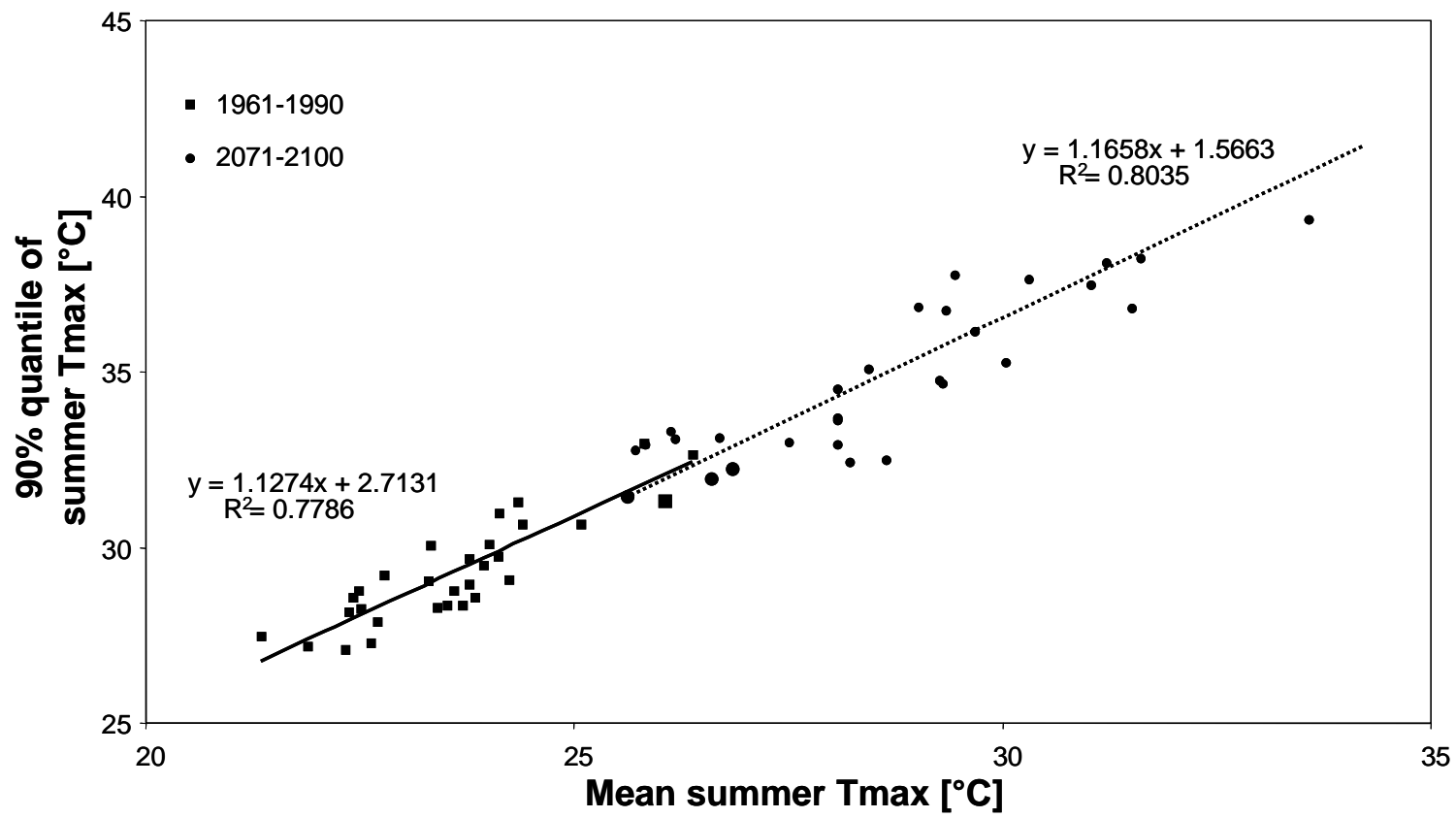

Figure 6. Relationship between summer mean maximum temperature and the $90 \%$ quantile of Tmax under current and future climatic conditions. Linear regression lines, their equations and their correlation coefficients are given for both the 1961-1990 (solid) and 2071-2100 (dashed) periods. 


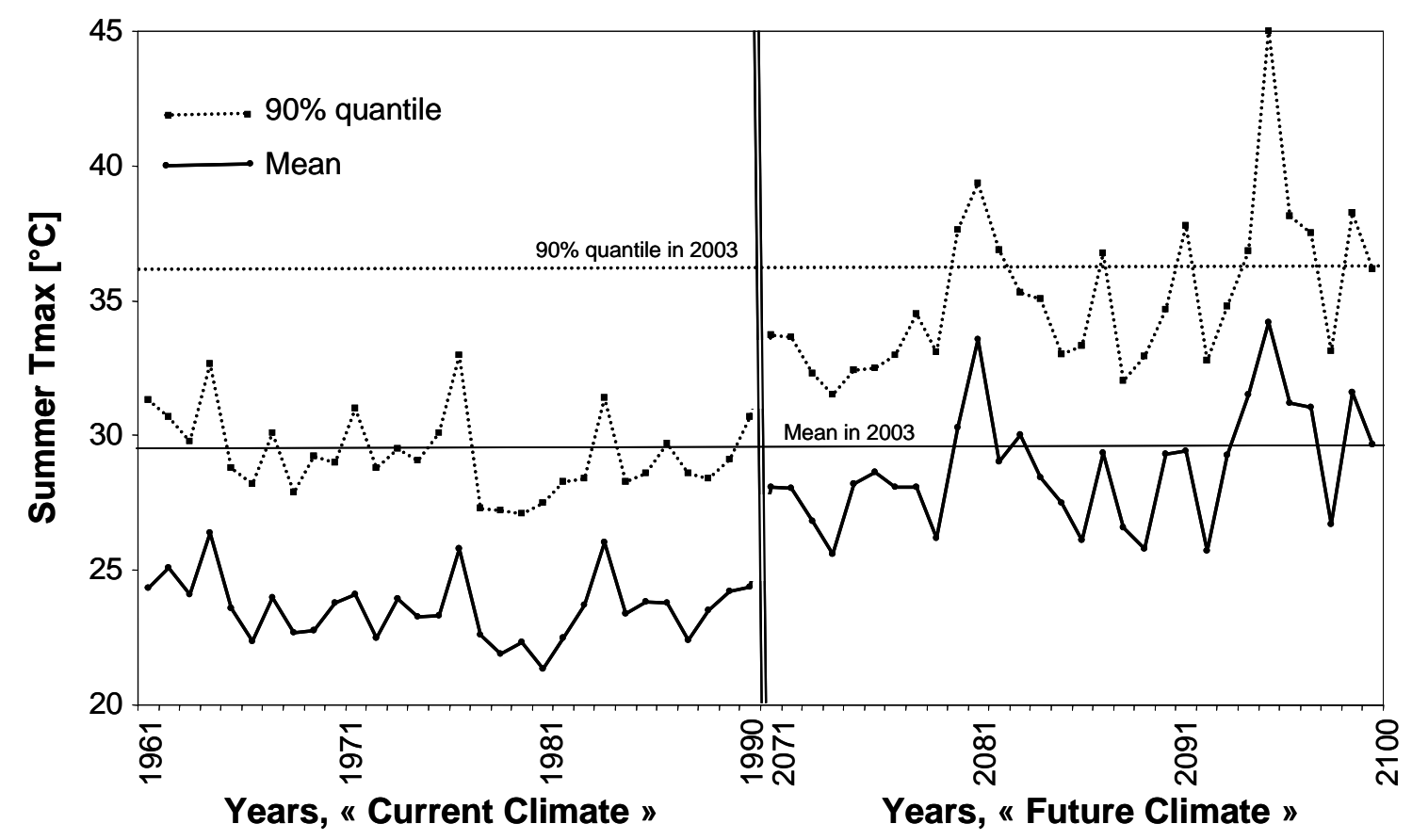

Figure 7. Comparisons of 30 years of summer mean maximum temperatures and the $90 \%$ quantile for the reference period 1961-1990 and the future period 2071-2100. The solid and dashed horizontal lines represent the mean and 90\% quantile for the 2003 summer, respectively. 